\title{
FULGÊNCIO SEM A LETRA ' $C$ ' TRADUÇÃO DO LIVRO III DO LIPOGRAMA DE AETATIBUS MUNDI ET HOMINIS
}

\author{
FULGENTIUS WITHOUT THE LETTER C \\ TRANSLATION OF BOOK III OF THE LIPOGRAM DE AETATIBUS MUNDI \\ ET HOMINIS
}

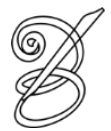 \\ Cristóvão José dos SANTOS JÚNIOR* \\ Universidade Federal da Bahia, Brasil
}

Resumo: Este trabalho debate o processo tradutório do terceiro livro (ausente C) do lipograma, De aetatibus mundi et hominis, atribuído ao escritor tardo-antigo e norte-africano Fábio Plancíades Fulgêncio (séc. V - VI), conhecido pelo epíteto de Mitógrafo, a partir da edição fixada por Rudolf Helm (1898). Nesta seção, Fulgêncio aborda a narrativa do mito da Torre de Babel, adotado como explicação para a origem da diversidade linguística. Interessante é perceber que o Mitógrafo evita o uso de unidades lexicais que contenham a letra 'c', o que está sendo cultivado na tradução proposta. Desse modo, a presente tradução também é relevante por denunciar a própria antiguidade do gênero lipogramático, que adquiriu significativa difusão no Concretismo, já situado no século XX. Palavras-chave: Torre de Babel. Fulgêncio. Antiguidade Tardia. Tradução Lipogramática. Escrita Constrangida.

Abstract: This work discusses the translation process of the third book (lacking C) of the lipogram De aetatibus mundi et hominis, attributed to the late-ancient and North African writer Fabius Planciades Fulgentius (V - VI century), known by the epithet of the Mythographer, from the edition fixed by Rudolf Helm (1898). In this section, Fulgentius addresses the narrative of the Tower of Babel myth, adopted as an explanation for the origin of linguistic diversity. Interestingly, the Mitograph avoids the use of lexical units containing the letter ' $c$ ', which is being cultivated in the proposed translation. Thus, the present translation is also relevant because it denounces the very antiquity of the lipogrammatic genre, which acquired significant diffusion in Concretism, already located in the twentieth century.

Keywords: Tower of Babel. Fulgentius. Late Antiquity. Lipogrammatic translation. Constrained Writing.

RECEBIDO EM: 07 de outubro de 2019

ACEITO EM: 18 de dezembro de 2019

PUBLICADO EM: janeiro 2020 


\section{O autor e a obra}

ábio Plancíades Fulgêncio foi um escritor norte-africano e tardo-antigo que viveu entre
o final do século V e início do século VI na época da dominação vandálica.
Infelizmente, pouco se sabe sobre sua vida, ante a sensível falta de subsídios para o estudo de sua biografia. Assim, muitos estudiosos tentam encontrar elementos em sua própria produção literária que sugiram alguma informação útil para o conhecimento desse autor, a exemplo de citações, que auxiliam na datação de seu legado, além de alusões intratextuais a locais e a pessoas.

Em decorrência da significativa difusão de suas Mythologiae, passou a ser conhecido como Mitógrafo, epíteto também adotado para diferenciá-lo de seu homônimo Ruspense, que é assim denominado por ter sido bispo da cidade de Ruspe. Considerado, por vezes, como um advogado ou professor, sobretudo em virtude de alguns aspectos estilísticos, a exemplo do largo uso de operadores argumentativos, Fulgêncio, o Mitógrafo, foi um escritor de notável repercussão artística, tendo influenciado os Mitógrafos do Vaticano, Dante Alighieri, Francesco Petrarca e Giovanni Boccaccio.

A fortuna crítica costuma lhe atribuir a elaboração de quatro obras: Mythologiae (Mitologias), Expositio sermonum antiquorum (A Elucidação de Palavras Antigas), Expositio Virgilianae continentiae (A Exposição dos conteúdos de Virgílio) e a De aetatibus mundi et hominis (Das idades do mundo e do homem). Ressalte-se, ainda, que as três primeiras produções já foram objeto de tradução para o português, respectivamente, por José Amarante (2019), Shirlei Almeida (2018) e Raul Moreira (2018), remanescendo um vácuo tradutório concernente à última.

Desse modo, a fim de preencher a lacuna existente quanto à De aetatibus, propõe-se, agora, uma tradução inédita de seu terceiro livro, marcado pela restrição em 'c'. Ante isso, o leitor precisa ter em mente que a obra em relevo se trata de um lipograma, gênero textual em que seu autor evita palavras que contenham uma determinada letra do alfabeto. O Mitógrafo a dividiu em 14 livros, dispensando, consecutivamente, em cada um deles, palavras que possuíssem registro nas 14 letras iniciais do alfabeto latino, indo, portanto, de 'a' a 'o'.

A tradução aqui proposta, por sua vez, é, em verdade, duplamente pioneira, pois corresponde à primeira para a língua portuguesa e à primeira do mundo realizada lipogramaticamente. Existe uma tradução para o inglês, feita por Whitbread (1971), e outra para o italiano, efetuada por Manca (2003), mas seus tradutores não cultivaram a constrição 
linguística. Esses suplementos textuais foram, entretanto, úteis para o processo de confecção das notas explicativas.

Note-se, ainda, que o amparo diegético de Fulgêncio diz respeito às escrituras sagradas cristãs, de tal sorte que ele descreve poeticamente um conjunto de passagens bíblicas. Nesta terceira seção (ausente C), o Mitógrafo traz à balha o mito da Torre de Babel, adotado como explicação para a origem da diversidade linguística. Destaque-se, por fim, que a edição consultada para o feito tradutório é aquela de referência da área, fixada por Helm (1898).

\section{Texto de partida latino}

Ordo adsumpti exigit operis, quo tertia mundi aetas hominisque similiter de trilustrio monstretur status seruato etiam tertiae litterae detrimento, ne non suo subripiens libro adsumti operis ordinem uexet. Qui quidem liber ex Babyloniae fundatione sumebit initium Ninique regis uel Sameramidis reginae temporibus; turrem etiam famoso ambitu fundamine destinatam totiusque populi aeque unitate atque linguae adunatione dispositam, quae tegulato latere et Puteolano puluere uel bitumine eminentior surgit astrorum sublimitati propinquior et ipsam pene lunarem suis pulsans angulis orbitam -ibi etenim dispersa uniuersaliter linguarum uarietas medium interemit operis adsumpti negotium, ut, dum quis extruens quod uellet inquireret, aliud qui deorsum fuerat obtulisset et, dum una esset adsumtio exurgentium, dispar fieret intentio operantium. O inmensa atque inaestimabilis diuina sententia. O profundi diuini sapientiae fontis. Vna uox, unus animus, unum etiam quod mortalitas adsumserat opus, et tamen in id quod gaudebat humanitas pluralitatem se repperisse ad implendum quod queperat, illud magis diuinitatis sapientia soluerat, qui uanos hominum impetus deridebat. Oboritur itaque inter sensuales mentium quiniones grande diuortium, ut aliud uox, aliud sensisset auditus. Exstitit lingua suae uoluntatis aduersa et quod loquendi sonus proruperat, aliud auris uelutsi extranea reputabat. Fit in una eademque membrorum unitate diuisio; petit lingua quod auditus nequaquam intellegit, dat auditus quod lingua omnimodis non petiit: et dum inter se uterque arietat sensus, semiplenum desertum est opus. Eo etiam tempore Babyloniae muri famosa opinione prosiliunt, quos Sameramis uanae laudis elata turgore fertur instaurasse. Nini enim sui mariti post obitum antiqui operis fundamina in meliorem laborando perduxit statum, quae quidem melius morum ordines pingeret quam murorum ambitus extendisset. Erat enim et suorum adulterorum mortifera <et> morientium adultera; libidinis summa: filii etiam in luxuriam feruens matris honore sepulto sibi nurus effecta est. Sed non mirum ut, quem adulterio genuerat talique patre pepererat natum, illum etiam sibi iungeret et maritum, ut, quem uuluae 
hiatu pariens gemendo produxerat, illius etiam semina libidinis ardoribus uaporata ingluuie inguinum transuorabat. Ninus etiam uxoris iniquitatibus non dissimilis et dignus pestilentis feminae matrimoniis primus etiam inuadens limites proximorum primus regnandi in mundo sumsit exordium, primus Squitaram tranquilla et serena quiete uiuentes inuadens terminos alieno uaporauit ferrum in sanguine. Ille humana negotia pura mansuetudine peragentia aduersa bellorum strage turbauit. Quid ergo horum temporum qualitas humano ordini similet, exquiramus. Quemadmodum mundo turris inmensitas in auras erigitur, ita homini iuuenalis aetas elationibus subleuatur. Illis mirum opus linguarum partitione destruitur, illo litterarum inbutamento stultitia terminatur; illis rudis loquella adsumtionem eripuit, isto rudis littera sensum aperuit. Sameramis totius libidinis ardore torretur, et pueritia luxuriae lampada inmoderatis augmentationibus uaporatur. Illis diuinitas linguas uerborum uarietate distinxit, istis sapientia ad ingenium prudentiae subleuauit. Mundo Babylonia instruitur regnandi primordium, homini sapientia tribuitur gubernationis ornamentum. Ibi Sameramis regnat aduersa iustitiae, isto aetas inminet lena luxuriae. Illa et libidinis amore torretur et sanguinis effusione polluitur, at uero aetas aut amando aestuat aut litigio fermentata uaporat. Illa

246 alienum rapax regnum inuadit, iste externae aut uxoris aut filiae quaerit amplexum. Ibi murorum ambitus in distentione admiranda porrigitur, isto iunentutis status uirtute etiam roborante firmatur. Quid igitur minus in huiusmodi similitudinibus aequiperabile forsan repperies? Sameramis flagitiorum fit domina, aetas [ruinae fit filia,] ruinae fit famula. Ergo homo mundus minor, in quo et natus ostenditur et similis repperitur; nil inter utrosque repperias forte distantiae. Restat ergo ut quarta mundi aetas atque hominis digerenda monstretur, quae quidem Abrahae similitudinem tempusque possideat.

\section{Texto de chegada em português}

A ordem da obra empreendida exige que seja narrada a idade do mundo de número três, e, semelhantemente, o estado do homem a partir do lustro posterior ao segundo, através também da mantida supressão da letra subsequente, de modo que a retirada a seu livro não arruíne a ordem da obra empreendida ${ }^{1}$.

Este livro, indubitavelmente, vai assumir sua origem a partir da gênese da Babilônia, quanto aos tempos do rei Nino, da rainha Semíramis e da torre destinada, desde sua base, ao famoso giro de palavras e disposta uniformemente na unidade de todo o povo e na fusão da língua ${ }^{2}$. 
A torre, a partir do ladrilho, da poeira de Pozzuoli e do betume, surge mais proeminente, mais próxima à sublimidade dos astros e quase atingindo a própria órbita lunar, através de suas extremidades $^{3}$. Ante isso, em realidade, a dispersa variabilidade das línguas, em ligame, suprime ao meio a atividade da obra empreendida, na medida em que, quando o obreiro indagasse o que desejava, aquele que estivesse embaixo lhe daria algo diverso, e, quando uma só fosse a vontade dos obreiros, o propósito dos operários resultaria diferente.

Ó imenso e inestimável juízo divino! Ó sabedorias de profundas fontes divinas! Uma só voz, um só ânimo, também uma só obra que os mortais tinham assumido, e, todavia, nisso, quanto mais a humanidade deleitava-se em ter obtido uma pluralidade de formas para terminar o que tinha instaurado, mais a sabedoria da Divinidade - que zombava dos vãos ímpetos dos homens - o dissolvia. Surge, portanto, um grande antagonismo no quinteto dos sentidos, de modo que se um indivíduo tivesse sentido a voz, o outro teria sentido o ouvido. A língua apresentou-se oposta à sua vontade, e o ouvido reputava estranho o que a fala havia fomentado 4 . E, ao mesmo tempo, nessa mesma unidade dos órgãos, a divisão é produzida. A língua pede o que o ouvido não entende de nenhuma forma. O ouvido dá o que a língua de nenhum modo pediu. E - enquanto, entre si, ambos os sentidos lutam - a obra é abandonada pela metade.

Até então, ao mesmo tempo, os muros despontam para a Babilônia junto a uma notabilidade infamante, e se fala que a arrogante Semíramis os teria feito por vanglória ${ }^{5}$. Em realidade, após o óbito de seu marido Nino, ela, empenhando-se, levou as bases daquela antiga obra a um estado melhor, mas, sem dúvidas, ela é que estaria melhor, se representasse os ditames das boas maneiras ao invés de ter prolongado o desejo de expansão dos muros.

Em verdade, ela era mortífera a seus amantes e adúltera dos moribundos, o topo da volúpia $^{6}$. Também a seu filho era ardente de luxúria e, sepultada a honra de mãe, se tornou nora de si mesma7 ${ }^{7}$ Mas não há nada de extraordinário - dado que agregaria a si por marido quem ela tinha gerado por adultério e por tal pai tinha parido um filho -, visto que, também deste - o qual ela tinha parido gemendo, dando à luz por uma fenda da vulva -, abrasada pelos ardores da volúpia, engolia o sêmen dos órgãos genitais pela garganta.

Também Nino, não diferente quanto às iniquidades da esposa e digno de matrimônios junto a uma mulher lesiva, pela primeira vez, invadindo os limites dos povos vizinhos, firmou a premissa da atividade de reinar. Pela primeira vez, invadindo as fronteiras dos antigos pastores nômades iranianos, que viviam em uma quietude tranquila e serena, abrasou o ferro em sangue estrangeiro. Ele agitou as atividades humanas que estavam em pura mansidão através do extermínio promovido nas guerras por adversários assassinos ${ }^{8}$. 
Investiguemos, então, de que modo a qualidade desses tempos se assemelha à natureza humana. A título de exemplo, no mundo, a imensidão da torre se ergue no ar. Dessa mesma maneira, a jovial idade se subleva ao homem, por meio da soberba. Àqueles, a surpreendente obra é destruída pela divisão das línguas. Àquela, através do ensino das letras, a estupidez termina. Àqueles, uma nova linguagem impediu a união. A esta, a palavra da Bíblia ilumina a mente ${ }^{9}$.

Semíramis inflama-se pelo ardor de toda volúpia, e a juventude se abrasa, desenfreadamente, pela fogueira da luxúria. Àqueles, a Divinidade distinguiu as línguas por meio da variedade das palavras. A estes, a sabedoria sublevou ao engenho do juízo.

No mundo, a Babilônia institui o primórdio da atividade de reinar. Ao homem, a sabedoria atribui honra para o governo. Ali Semíramis reina avessa à justiça. A este, domina a idade, sedutora da luxúria. Ela não só se inflama através do amor da volúpia, mas também se suja pelo derramamento de sangue. Ademais, em verdade, a idade ou ferve amando, ou se abrasa inflamada no litígio ${ }^{10}$. Aquela invade ávida o reino estrangeiro, este vai atrás do amplexo de uma outra esposa ou filha ${ }^{11}$. Ali se estende o âmbito dos muros, admiráveis em dimensão. A este, o estado de juventude também se assegura robusto pela virtude. O que, então, por exemplo, julgarás ao menos equiparável em semelhanças a tal natureza? Semíramis se torna senhora dos delitos, e esta idade se torna serva da ruína.

O homem é, portanto, um mundo menor, de onde não só se mostra filho, mas também se nota semelhante, e não repararias, entre ambos, nada muito distante. Resta, então, que se mostre a quarta idade do mundo e do homem, a qual deve ser delineada, e que, ademais, abrangeria o tempo de Abraão e suas similitudes.

\section{REFERÊNCIAS}

ALMEIDA, Shirlei. A 'Expositio Sermonum Antiquorum', de Fulgêncio, o Mitógrafo: estudo introdutório, tradução e notas. Dissertação (Mestrado em Literatura e Cultura) PPGLitCult, Universidade Federal da Bahia, Salvador, 2018. Disponível em: http://repositorio.ufba.br/ri/handle/ri/27547. Acesso em: 2 jan. 2020.

AMARANTE, José. O livro das Mitologias de Fulgêncio. Os mitos clássicos e a filosofia moral cristã. Salvador: Edufba, 2019.

FULGENTIUS, Fabius. Opera. Edição de Rudolf Helm. Lipsiae: Teubner, 1898.

MANCA, Massimo. Le età del mondo e dell'uomo. Allesandria: Edizioni dell'Orso, 2003. 
MOREIRA, Raul. A “Exposição dos conteúdos de Virgílio", de Fulgêncio: estudo introdutório e tradução anotada. Dissertação (Mestrado em Literatura e Cultura) PPGLitCult, Universidade Federal da Bahia, Salvador, 2018. Disponível em: http://repositorio.ufba.br/ri/handle/ri/26692. Acesso em: 2 jan. 2020.

WHITBREAD, Leslie George. Fulgentius, The Mithographer. Ohio: State University Press, 1971.

* Cristóvão José dos SANTOS JÚNIOR - Doutorando em Literatura e Cultura e mestre em Literatura e Cultura (2019) pela Universidade Federal da Bahia (UFBA). Graduado em Direito (2017) e graduando em Letras Clássicas (Latim e Grego Antigo) pela Universidade Federal da Bahia. Salvador, Bahia, Brasil.

Currículo acadêmico: http://lattes.cnpq.br/0262703551113790

ORCID: https://orcid.org/0000-0002-5797-7192

E-mail: cristovao_jsjb@ hotmail.com

${ }^{1}$ Percebe-se, no texto de partida latino, um paralelismo com aliteração em ' $t$ ' estruturada a partir dos termos 'tertia mundi aetas' ('terceira idade do mundo'), 'trilustrio' ('terceiro lustro') e 'tertiae litterae' ('terceira letra'). Ocorre que, em razão da restrição em ' $c$ ', não foi possível registrar essas escolhas tradutórias, instante em que se optou por subterfúgios circunloquiais, como "idade de número três" ao invés de "terceira idade" e "lustro posterior ao segundo", ao invés de "terceiro lustro". Para o último caso, a saída foi ainda mais particular, estando vinculada a uma leitura dos livros em conjunto, ressaltando o caráter consecutivo do lipograma. Assim, utilizase "letra subsequente", ao invés de "terceira letra"

${ }^{2}$ Em 'vai assumir', buscou-se adotar o futuro perifrástico ao invés do simples, a fim de evidenciar o atual estado de concorrência linguística, ressaltando, igualmente, uma marca de coloquialidade. O uso do termo 'gênese' é oportuno por reforçar o arcabouço linguístico de prisma litúrgico. Ademais, conforme Whitbread (1971), Semíramis, rainha mitológica da Assíria, foi descrita por Heródoto, Diodoro da Sicília e Orosius, que, por sua vez, foi seguido por Fulgêncio em determinados aspectos.

${ }^{3}$ Faz-se alusão à pozolana, que recebe esse nome em alusão à comuna italiana de Pozzuoli. Ela diz respeito a um material de origem piroclástica, usado em construções civis.

${ }^{4}$ A tradução de 'reputabat' por 'reputava' exerce tripla função, na medida em que configura arcaísmo de cunho latinizante, permite a incolumidade da estrutura lipogramática (considerava) e também contribui com a assunção poética, por parte do narrador, de alguém que detém conhecimentos jurídicos, visto ser comum nesse campo seu emprego.

${ }^{5}$ Vide Orosius 1.2.

${ }^{6}$ Note-se a repetição do operador argumentativo 'enim'. Ademais, deve-se recordar que, no primeiro livro, traduziu-se, em geral, com o vocábulo 'decerto', o que foi modificado por 'em verdade' por razões lipogramáticas.

${ }^{7}$ Vide Orosius 1.4.7.

${ }^{8}$ Vide Orosius 1.4. Em latim, a forma adotada foi "pestilentis feminae" ('mulher pestilenta'). Ocorre que o termo 'pestilenta', na língua portuguesa, está muito carregado do sentido de 'fedorenta', opção que conferiria até um tom burlesco à tradução. Tendo isso em vista, optou-se pela palavra 'lesiva', a qual é de natureza jurídica. É curioso perceber que o vocábulo latino 'exordium'é típico da retórica. Em atenção a esse elemento - que denota a apropriação do autor de conhecimentos de mais um campo do saber - foi escolhida a palavra 'premissa', comum nos estudos de retórica hodiernos. Assim, mesmo em face de sincronias distintas, buscou-se uma aproximação dos termos pelo âmbito epistêmico que ocupam. Fulgêncio adota o termo 'Squitarum', que se refere ao povo iraniano cita, o qual não pode ser expressamente referenciado por nítida razão lipogramática.

9'Littera' possui uma conotação religiosa, também sendo usada no sentido de Bíblia ou escrituras sagradas.

${ }^{10}$ Sublinhe-se, inclusive, o uso de palavras comuns na seara jurídica, o que reforça a diretriz imagética relativa à profissão de seu autor ficcionalizado.

${ }^{11}$ Em latim, é evidente o caráter aliterante com repetição de /ks/, grafado ' $\mathrm{x}$ ': rapax regnum inuadit, iste externae aut uxoris aut filiae quaerit amplexum. 